\title{
OPTIMIZATION OF CLIC TRANSFER STRUCTURE (CTS) DESIGN TO MEET NEW DRIVE BEAM PARAMETERS
}

\section{A. Millich, CERN-SL, CH-1211 Geneva 23}

\section{INTRODUCTION}

In the original CTS design [1] the $2.8 \mathrm{~mm}$-wide slit, joining the cylindrical beam chamber to the teeth-loaded rectangular waveguides provided a sufficient coupling for the $160 \mathrm{nC}$ drive-beam bunches to deposit $40 \mathrm{MW}$ of $30 \mathrm{GHz}$ power in the waveguides. The drive-beam generation studies have recently evolved towards schemes which envisage an increased number of bunches at reduced charge per bunch [2]. In order to cope with the reduced beam intensity while maintaining the correct power output level, the CTS design has been modified to increase the beam coupling parameter. Moreover, the new CLIC Test Facility (CTF2) requires transfer structures with even higher beam coupling because of the reduced bunch frequency $(3 \mathrm{GHz})$ [3]. Additional modifications to the original design were required by manufacturing, which imposed the presence of round lips at the slit edges [4]. We have simulated the new CTS by means of MAFIA in order to explore the range of variation of the coupling parameter with slit aperture, and optimized the design to meet the requirements of both the new drive beam and the CTF2. We report here the results of the simulation studies.

\section{CTS COUPLING FACTORS FOR CLIC AND CTF2}

In the reference scheme for CLIC, the drive beam is formed by four trains of 22 bunchlets each, separated in time by $2.84 \mathrm{~ns}$. The Gaussian bunchlets have $\sigma=1 \mathrm{~mm}$, a $30 \mathrm{nC}$ charge, and a spacing of one $30 \mathrm{GHz}$ period. After the traversal of one bunchlet train, the CTS received the energy

$$
\mathrm{U}=(\mathrm{R} / \mathrm{Q}) \mathrm{q}^{2} \mathrm{~F}^{2}(\sigma) \omega / 2 \quad(\mathrm{VAs})
$$

where $\mathrm{R} / \mathrm{Q}$ is the mode coupling factor, $\mathrm{q}=660 \mathrm{nC}$ is the charge in one train, $\mathrm{F}(\sigma)=0.82$ is a function of the bunch length, and $\omega=2 \pi \mathrm{f}$ is the angular frequency of the coupled mode. The energy $U$ is induced in one burst during the traversal of the bunchlet train and discharges uniformly during $2.84 \mathrm{~ns}$ at the rate imposed by the mode group velocity of $0.3 c$. Just before the CTS discharges completely, the next bunchlet train traverses the structure and again fills it with energy. The CTS thus acts as a pulse stretcher and delivers a uniform power pulse $11.4 \mathrm{~ns}$ long to fill two CLIC Accelerating Structures (CASs), one from each waveguide. The power needed to fill the two CASs is $90 \mathrm{MW}$, which requires $4 \mathrm{U}=1.02 \mathrm{VAs}$, and $\mathrm{R} / \mathrm{Q}=9.4 \Omega /$ structure or $\mathrm{R}^{\prime} / \mathrm{Q}=$ $23.0 \Omega / \mathrm{m}$, as the CTS is $41 \mathrm{~cm}$ long.

The main goal of the CTF2 experiment is to use one CTS to provide $50 \mathrm{MW}$ power pulses to one CAS by combining the two waveguide outputs. In this case the drive beam will be formed by a continuous train of bunchlets separated by a 3 $\mathrm{GHz}$ period or $333.3 \mathrm{ps}$. The charge which traverses one CTS during $2.84 \mathrm{~ns}$ will initially be limited in CTF2 to $200 \mathrm{nC}$, so that solving Eq. (1) for R/Q and substituting $\mathrm{U}=\mathrm{dP}$ with $\mathrm{P}=$ $50 \mathrm{MW}$ and $\mathrm{d}=2.84 \mathrm{~ns}$ we get for the CTS coupling parameter the value

$$
\mathrm{R} / \mathrm{Q}=56.7 \Omega / \text { structure or } \mathrm{R}^{\prime} / \mathrm{Q}=138.0 \Omega / \mathrm{m} \text {. }
$$

\section{THE NEW CTS GEOMETRY}

Figure 1 shows a six-cell section of the CTS as simulated by MAFIA [5].

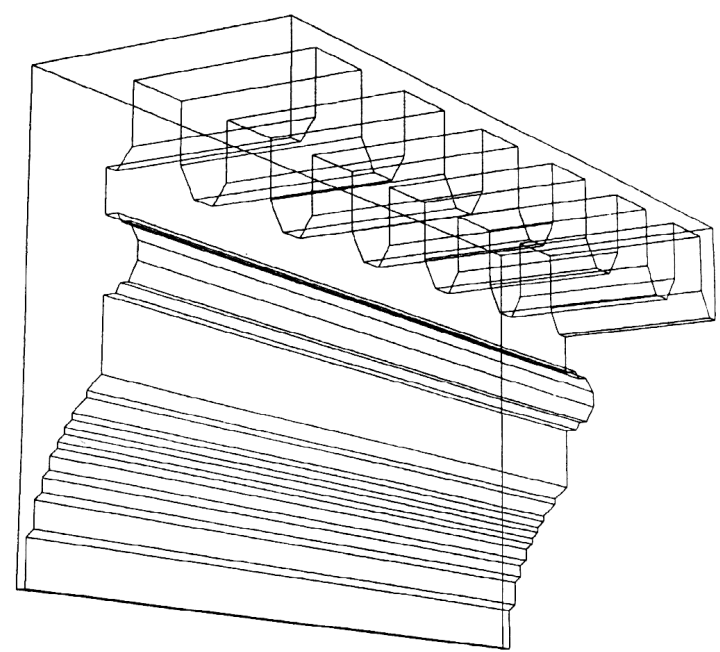

Figure 1: Six cells of CTS as simulated by MAFIA (upper left corner shown).

We notice the presence of the rounded lips, which mark the separation of the beam chamber from the teeth-loaded waveguides. The main geometrical parameters of the CTS are:

$\begin{array}{ll}\text { Beam chamber radius } & 6.000 \mathrm{~mm} \\ \text { Waveguide width } & 8.600 \mathrm{~mm} \\ \text { Slit aperture* } & 3.0 \text { to } 7.000 \mathrm{~mm} \\ \text { Lip radius } & 0.800 \mathrm{~mm} \\ \text { Waveguide height } & 3.000 \mathrm{~mm} \\ \text { Teeth spacing } & 3.332 \mathrm{~mm} \\ \text { Teeth height } & 2.000 \mathrm{~mm} \\ \text { Teeth thickness } & 1.667 \mathrm{~mm} \\ \text { CTS length } & 410.0 \mathrm{~mm} \\ \text { *may vary to change the coupling }\end{array}$

The maximum aperture between the lips' edges is given by the waveguide width minus twice the lip radius, or $8.6-1.6=7.0 \mathrm{~mm}$. We have explored the variation of the main RF parameters with slit aperture increasing from 3.0 to $7.0 \mathrm{~mm}$ while keeping all other parameters constant. Table 1 summarizes the results obtained. 
Table 1

\begin{tabular}{|c|c|c|r|r|c|}
\hline $\begin{array}{c}\text { Slit } \\
(\mathrm{mm})\end{array}$ & $\begin{array}{c}\mathrm{f} \\
(\mathrm{GHz})\end{array}$ & $\mathrm{Q}$ & $\begin{array}{c}\mathrm{R}^{\prime} / \mathrm{Q} \\
(\Omega / \mathrm{m})\end{array}$ & $\begin{array}{c}\mathrm{E}_{\mathrm{W}} / \mathrm{E}_{\mathrm{t}} \\
(\%)\end{array}$ & $\begin{array}{c}\hat{\mathrm{W}}_{\mathrm{z}}^{\prime} \\
(V / p C / m)\end{array}$ \\
\hline 3.0 & 28.85 & 2651 & 2.40 & 99.70 & 0.95 \\
\hline 4.0 & 29.95 & 3143 & 14.42 & 98.60 & 2.65 \\
\hline 5.0 & 30.94 & 3538 & 89.61 & 94.67 & 7.25 \\
\hline 6.0 & 30.88 & 3832 & 149.75 & 92.44 & 12.34 \\
\hline 7.0 & 30.35 & 4025 & 178.20 & 88.95 & 19.10 \\
\hline
\end{tabular}

The fifth column in the table gives the ratio of the energy of the mode in the waveguides over the total mode energy. This is an important parameter as it determines the efficiency of the power extraction from the beam. The sixth column shows the peak value of the longitudinal wake potential for a Gaussian bunch with $\sigma=1 \mathrm{~mm}$ traversing $1 \mathrm{~m}$ of structure, computed using the time domain module T3320 of MAFIA.

\section{OPTIMIZATION OF THE CTS FOR THE CLIC REFERENCE SCHEME}

From the results shown in Table 1 it appears that a slit aperture of about $4.2 \mathrm{~mm}$ would provide the required CTS coupling of $23 \Omega / \mathrm{m}$ for the reference scheme, albeit at the expense of relatively high losses, as shown by the low Q value. We have preferred to keep a wider slit aperture and to search for the required coupling parameter value by increasing the waveguide height. The search has been successful and the results are:

$\begin{array}{ll}\text { Slit aperture: } & 5.8 \mathrm{~mm} \\ \text { Waveguide height: } & 4.0 \mathrm{~mm} \\ \text { Mode frequency: } & 29.993 \mathrm{GHz} \\ \text { Q factor: } & 3942 \\ \mathrm{R}^{\prime} / \mathrm{Q}: & 25.1 \Omega / \mathrm{m} \\ \mathrm{E}_{\mathrm{W}} / \mathrm{E}_{\mathrm{t}}: & 97.6 \% \\ \mathrm{~W}_{\mathrm{z}}^{\prime}: & 4.6 \mathrm{~V} / \mathrm{pC} / \mathrm{m} \\ \mathrm{vg}_{\mathrm{g}} / \mathrm{c}: & 0.29\end{array}$

The frequency is not exactly at the nominal value but is well within the tolerance imposed by our mesh resolution.

\section{OPTIMIZATION OF THE CTS FOR CTF2}

The solution to the CTF2 requirement $\left(\mathrm{R}^{\prime} / \mathrm{Q}=138 \Omega / \mathrm{m}\right)$ was found by lowering the waveguide height (to increase the coupling parameter) and by increasing the teeth height (to lower the coupled mode frequency). The results were:

$\begin{array}{ll}\text { Slit aperture: } & 7.0 \mathrm{~mm} \\ \text { Waveguide height: } & 2.6 \mathrm{~mm} \\ \text { Teeth height: } & 2.11 \mathrm{~mm} \\ \text { Mode frequency: } & 30.016 \mathrm{GHz} \\ \text { Q factor: } & 3786.0 \\ \mathrm{R}^{\prime} / \mathrm{Q}: & 146.0 \Omega / \mathrm{m} \\ \mathrm{E}_{\mathrm{W}} / \mathrm{E}_{\mathrm{t}}: & 90.2 \% \\ \mathrm{~W}_{\mathrm{z}}^{\prime}: & 28.1 \mathrm{~V} / \mathrm{pC} / \mathrm{m} \\ \mathrm{vg}_{\mathrm{g}} / c: & 0.27\end{array}$

The shape of the longitudinal wake excited by one bunch traversal of a 12-cell section of CTS shows that the bunch interacts mainly with a single mode (Fig. 2).

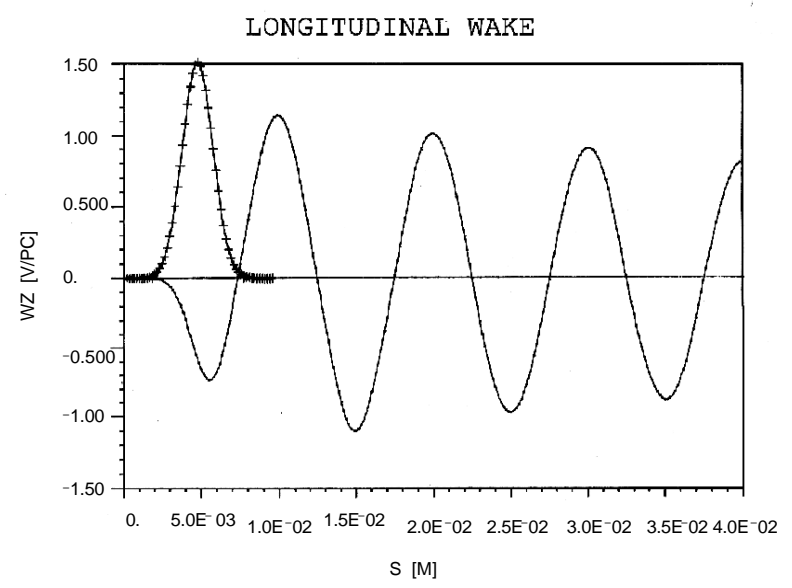

Figure 2: Longitudinal wake.

It is therefore possible to compare the peak value of the longitudinal wake with the coupling factor of the synchronous $2 \pi / 3$ mode by means of the relation

$$
\left(\mathrm{R}^{\prime} / \mathrm{Q}\right) \omega \mathrm{e}^{-1 / 2(\omega \sigma / \mathrm{c})^{2}}=\hat{\mathrm{W}}_{\mathrm{Z}}^{\prime} \text {. }
$$

The result for the left-hand side is $22.60 \mathrm{~V} / \mathrm{pC} / \mathrm{m}$, which compares fairly well with the value of $28.1 \mathrm{~V} / \mathrm{pC} / \mathrm{m}$ for the peak of the longitudinal wake.

\section{CONCLUSION}

With our simulation study we have shown that it is possible to increase the CTS beam coupling over a wide range without destroying the chosen mode for power transfer. We have found the frequency and coupling factor characteristics as a function of the slit aperture and have optimized the geometry to meet the requirements imposed by the drive beam properties in both the reference CLIC scheme and the CTF2 experiment. We have shown that a higher beam coupling brings stronger wakefields and a less favourable mode energy distribution between the wave-guides and the beam chamber. This last drawback may, however, be overcome by means of an optimal design of the output waveguide couplers, which recuperate part of the energy in the beam chamber.

\section{REFERENCES}

[1] G. Carron, L. Thorndahl, Progress with the CLIC Transfer Structure (CTS), Proceedings of EPAC 94, London, UK.

[2] B. Autin et al., CLIC Drive Beam Generation, a feasibility study, Proceedings of EPAC 94, London, UK.

[3] R. Bossart et al., CTF Developments and Results, these proceedings.

[4] G. Carron, L. Thorndahl, private communications.

[5] MAFIA 3.2 Reference Manual, the MAFIA Collaboration, 1994. 